\title{
A Case of Pregnancy with Ebstein's Anomaly
}

\author{
RUMAN U $^{\mathrm{a}}$, CHOWDHURY TS ${ }^{\mathrm{b}}$, NESSA ${ }^{\mathrm{c}}$, SULTANA ${ }^{\mathrm{d}}$, NARGIS S
}

\begin{abstract}
A 26- years old multigravida, developed palpitation and dizziness at $30^{\text {th }}$ gestational weeks and was got admitted in BIRDEM hospital. Her ECG showed ST-depression (anteriors).Echocardiogram revealed severe atrialized right ventricle, non-restrictive ASD secundum. She was diagnosed
\end{abstract}

\section{Introduction}

Ebstein's anomaly is a congenital malformation of the heart that is characterized by apical displacement of the septal and posterior tricuspid valve leaflets, leading to atrialization of the right ventricle with a variable degree of malformation and displacement of the anterior leaflet. For those female patients with the anomaly who survive to adult life there is little information available about pregnancy, maternal complications, and fetal outcome. Pregnancy in women with mild and surgically corrected Ebstein's anomaly is well tolerated. It is associated with an increased risk of prematurity, fetal loss and congenital heart disease in the offspring. In addition, a significantly lower birth weight is found in the offspring of cyanotic versus acyanotic women with Ebstein's anomaly. So, early diagnosis and correction of the lesion can improve maternal and fetal outcome significantly.

\section{Case report}

Mrs. X, 26 years old multigravida from Dinajpur with pregnancy of $30^{+4}$ weeks was referred to BIRDEM Hospital with complaints of dizziness and palpitation for 10 days. She was on regular antenatal check-up. Her ante natal period was relatively uneventful until 28 weeks when she developed palpitation. She was non diabetic and normotensive. She was regularly immunized as per schedule. She was a regularly menstruating woman prior

a. Dr. Umme Ruman, FCPS, Registrar, Anwar Khan Modern Medical College and Hospital

b. Dr. Tanzeem Sabina Chowdhury, FCPS, MRCOG, Assistant Professor, Gynae and Obstetrics, Ibrahim Medical College and BIRDEM General Hospital,Shahbag,Dhaka-1000, Bangladesh.

c. Dr. Maherunnessa, FCPS Registrar, Gynae and Obstetrics, Ibrahim Medical College and BIRDEM General Hospital, Shahbag, Dhaka-1000,Bangladesh.

d. Dr. Rebeka Sultana, FCPS, Assistant Professor, Gyn. \& Obs. Enam Medical College \& Hospital, Dhaka

e. Dr. Sohelee Nargis, Medical Officer, Gynae and Obstetrics, Ibrahim Medical College and BIRDEM General Hospital, Shahbag, Dhaka-1000, Bangladesh

Address of Correspondence: Dr. Umme Ruman, FCPS, Registrar, Anwar Khan Modern Medical College and Hospital, E-mail: rumman09umme@yahoo.com

Received: 12 August 2013

Acceptance: 22 December, 2014 as a case of pregnancy with Ebstein's anomaly with ASD. At $34^{\text {th }}$ gestational week, she underwent spontaneous pre-term labour and gave birth to a still born. She developed peripheral cyanosis during pregnancy which subsided few days after delivery.

(Birdem Med J 2015; 5(1): 46-49)

to conception. She was married for 8 years having history of two consecutive intra uterine fetal death (IUFD). First IUFD was at 32 weeks at 2007 and second one was at 34 weeks at 2008. Both were delivered vaginally. She said that she developed peripheral cyanosis in her previous pregnancies but she did not consult with any physicians. She was a home maker and came from a poor family. At the time of admission, she was not anaemic. There was no oedema. There was cyanosis and clubbing [Fig 2 and Fig 3]. Her vital parameters were normal.

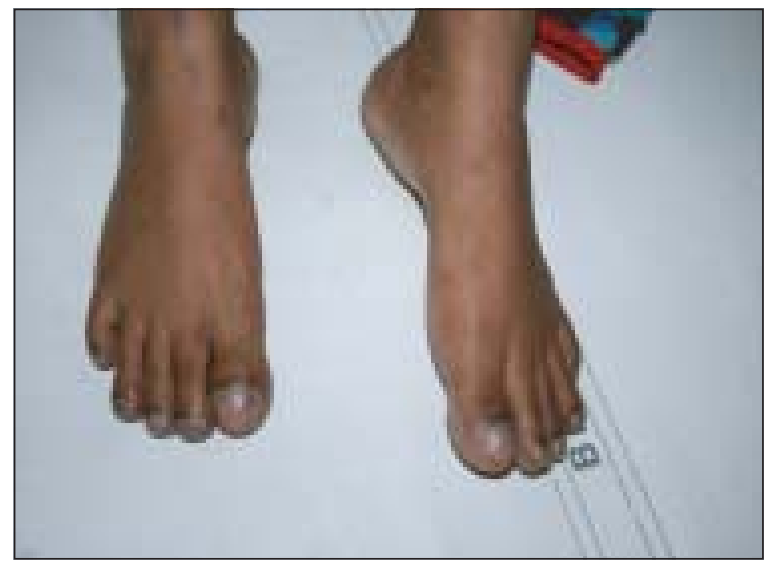

Fig 1(a): Clubbing

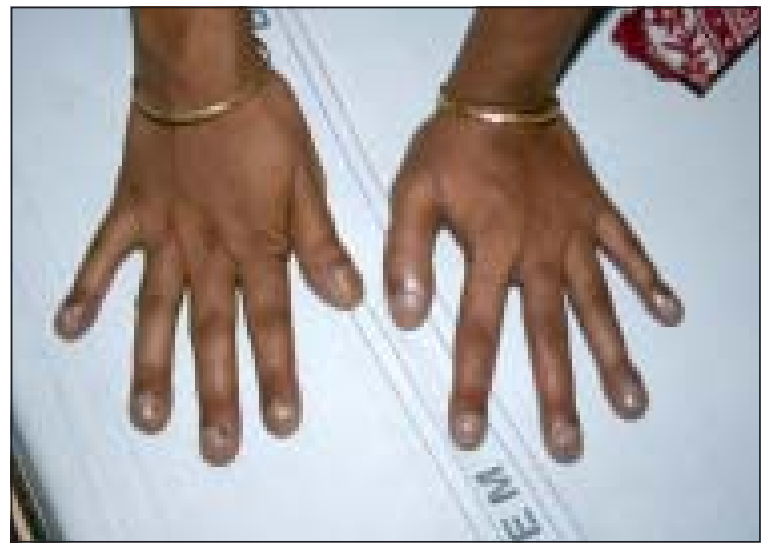

Fig 1(b):- Clubbing 
Abdomen was enlarged with gravid uterus with fundal height corresponding to 30 weeks gestation. Fetal heart rate was $144 \mathrm{~b} / \mathrm{min}$.Cardiovascular system examination revealed no abnormality except splitting of $2^{\text {nd }}$ heart sound. Investigations were done after admission and it revealed hemoglobin was $12.6 \mathrm{gm} / \mathrm{dl}$. ECG showed slightly depresed ST segment in anterior leads [Fig 2].

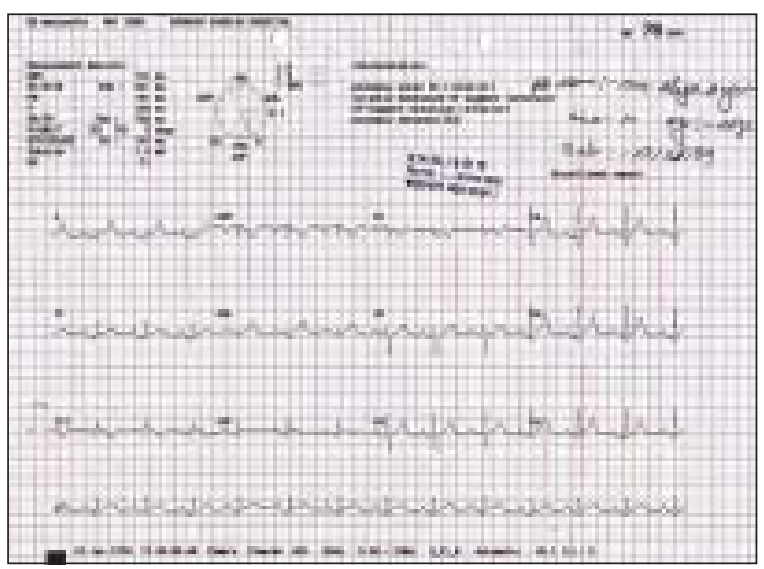

Fig -2: ECG showing depressed ST segment in anterior leads

Echocardiography showed features suggestive of Ebstein's anomaly, severely atrialized right ventricle, non restrictive ASD secundum, moderate tricuspid regurgitation, ejection fraction $60 \%$ [Fig 3].

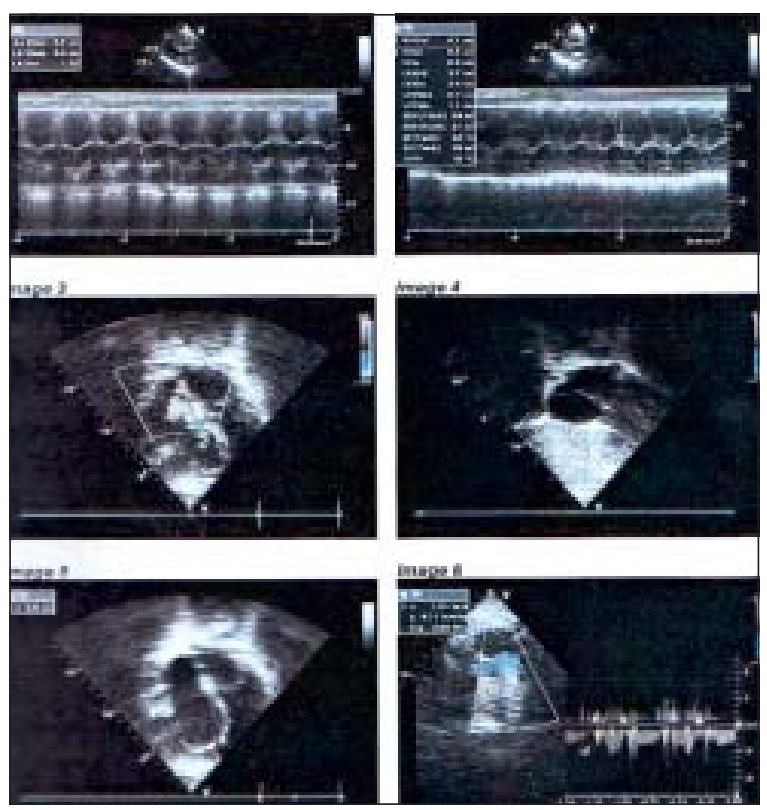

Fig-3: Echocardiography-Atrialized right ventricle
Ultrasonography of uterus showed, single alive intra uterine pregnancy of 29wks with sluggish movement. Cardiac pulsation was regular(146b/min). Placenta was posterior and away from os and swollen in appearance. Amniotic fluid index was $7 \mathrm{~cm}$.Biophysical profile was $6 / 8$. So, our diagnosis was $3^{\text {rd }}$ gravid $30+4$ weeks pregnancy with oligohydramnios with Ebstein's anomaly with ASD with moderate tricuspid regurgitation. She was treated with bed rest, salt restricted diet, regular fetal monitoring and daily cardiotocography. Cardiology consultation was taken and she was given oral frusemide, spironolactone, oral penicillin and diazepam. During hospital admission, she developed two episodes of dizziness and palpitation.She was treated with $\mathrm{O}_{2}$ inhalation and injectable hydrocortisone. She was advised to have termination of pregnancy followed by surgical correction of Ebstein's anomaly. Any surgical procedure under anesthesia was considered as high risk and termination by induction with drugs causing tachycardia also was considered risky. so, it was decided to continue the pregnancy till spontaneous onset of labour as the fetus was already compromized. The patient and her attendant was in favour of termination of pregnancy by caesarean section and refused for further continuation of pregnancy. So she was discharged on request but was communicated over phone from time to time. Patient got admitted in another hospital at 34 weeks of her gestation with labour pain and delivered a dead foetus.

\section{Discussion}

First described by Wilhelm Ebstein in 1866, Ebstein's anomaly is a congenital malformation of the heart, characterised by apical displacement of the septal and posterior tricuspid valve leaflets, leading to part of the right ventricle becoming part of the right atrium, with a variable degree of malformation and displacement of the anterior leaflet. This accounts for less than $1 \%$ of cases of congenital heart diseases. ${ }^{1}$ True prevalence is unknown because mild forms often remain undiagnosed. Environmental factors implicated in aetiology include maternal ingestion of lithium or benzodiazepine and maternal history of miscarriage. ${ }^{2}$ Increased incidence is observed in Caucasians.

Ebstein's anomaly presents with a spectrum of congenital abnormalities of the tricuspid valve and the right ventricle. ${ }^{3}$ The abnormality of the tricuspid valve leads to tricuspid regurgitation. The degree of tricuspid regurgitation is variable, ranging from mild to severe 
regurgitation. Presentation is often between the ages of 10 and 30 years but can present at various stages of life. The embryological development of tricuspid valve leaflets and chordae involves undermining of the right ventricular free wall. This process continues to the level of the atrioventricular (AV) junction. In Ebstein anomaly, this process of undermining is incomplete and falls short of reaching the level of the AV junction. In addition, the apical portions of the valve tissue, which normally undergo resorption, fail to resorb completely. This results in distortion and displacement of the tricuspid valve leaflets, and a part of the right ventricle becomes atrialized. In one study involving 50 hearts with the anomaly, the entire right ventricle was found to be morphologically abnormal. ${ }^{4}$

Ebstein anomaly is commonly associated with other congenital, structural, or conduction system disease, including intracardiac shunts, valvular lesions, and accessory conduction pathways eg, Wolff-ParkinsonWhite (WPW) syndrome. J E Donelly ${ }^{5}$ in 1991 studied forty two pregnancies in 12 women with Ebstein's anomaly. The mothers' cardiac lesions were assessed on the basis of symptoms, the presence of cyanosis or arrhythmia, and by echocardiographic grading of severity. In the absence of important maternal cyanosis or arrhythmia, pregnancy was well tolerated. Neonatal outcome was good though there was an increased risk of prematurity and dysmaturity in the babies born to mothers with cyanosis. In adult life, Ebstein anomaly presents with fatigue, exertional dyspnea, cyanosis, tricuspid regurgitation and/or right heart failure, and palpitations; arrhythmias are common. The raised concentrations of circulating catecholamines in pregnancy will exacerbate any predisposition to arrhythmias and major arrythmias may occur, particularly if there is maternal hypoxaemia or stress. Cyanosis may appear for the first time in adult life. In pregnancy, dyspnoea and palpitation may occur at the end of second trimester .Echocardiogram is the criterion standard for diagnosis. 12 -lead ECG shows normal sinus pattern, prolonged PR interval, Intermittently SVT, paroxysmal SVT, atrial flutter, atrial fibrillation, ventricular tachycardia, abnormal $\mathrm{P}$ waves consistent with right atrial enlargement. Treatment options include medical therapy, radiofrequency ablation, and surgical therapy. Surgical care includes correction of the underlying tricuspid valve and right ventricular abnormalities, correction of any associated intracardiac defects, palliative procedures in early days of life as a bridge to more definitive surgical treatment later, and surgical treatment of associated arrhythmias. Complete repair of Ebstein anomaly in symptomatic neonates has been shown to be feasible, with good early and late survival and excellent functional status. ${ }^{6}$

The prognosis depends on severity of the anomaly, degree of tricuspid regurgitation, degree of heart failure, associated anatomical defects and associated arrhythmias. ${ }^{7}$ Patients presenting in infancy generally have severe disease and a poor prognosis. ${ }^{8}$ However the prognosis for neonatal Ebstein's anomaly has improved with modern surgical techniques. ${ }^{9}$

There are few published reports on pregnancy in women with Ebstein's anomaly. The largest series was reported by Radford et al, where successful pregnancy occurred in six women who had a total of 12 children. ${ }^{9}$ In two large studies on congenital heart disease in pregnancy (total 357 women) five women had Ebstein's anomaly and three of them had cyanosis. ${ }^{23}$ They had eight pregnancies and there were two fetal deaths, both in infants born to women with cyanosis. Several case reports emphasise the potential complications in pregnancy in women with Ebstein's anomaly. ${ }^{10}$ However, in each one the patients were symptom free until the third trimester and mother and infant survived. Though pregnancy was well tolerated in patients in this study and fetal outcome was good, five women including three in whom there were no strong medical or obstetric indications had been advised not to have further pregnancies because of their cardiac anomaly. This uncertainty about the natural history of the condition in pregnancy is reflected in a report of unnecessary termination of pregnancy because of the diagnosis of Ebstein's anomaly in the mother. Matemal cyanotic congenital heart disease has been shown to be associated with prematurity and low birth weight and with infant survival rates of $50-55 \% .{ }^{11}$ The combined effects of maternal hypoxaemia and haemodynamic instability make the infant liable to intrauterine fetal growth retardation and even death.

\section{Conclusion}

Pregnancy with Ebstein's anomaly (unrepaired or repaired) poses potential risks to both mother and foetus. The presence of arrhythmia or cyanosis in the mother is 
associated with increased maternal and fetal risk. Pregnancy is usually not advised to a patient with Ebstein's anomaly but if a patient become so, closer maternal and fetal observation by both obstetrician and cardiologist during pregnancy and delivery is required.

\section{References}

1. Attenhofer Jost CH, Connolly HM, Edwards WD, Hayes D, Warnes CA, Danielson GK; Ebstein's anomaly - review of a multifaceted congenital cardiac condition. Swiss Med Wkly 2005;135(19-20):269-81.

2. Correa-Villaseñor A, Ferencz C, Neill CA, Wilson PD, Boughman JA; Ebstein's malformation of the tricuspid valve: genetic and environmental factors. The BaltimoreWashington Infant Study Group . Teratology 1994 ;50(2):137-47.

3. Celermajer DS, Bull C, Till JA, Cullen S, Vassillikos VP, Su- llivan ID, Allan L, Nihoyannopoulos $P$, Somerville $J$, Dean- field JE ; Ebstein's anomaly: presentation and outcome from fetus to adult. J Am Coll Cardiol 1994;23(1):170-76.

4. Muñoz- Castellanos L, Espinola-Zavaleta N, Kuri-Nivón M, Keirns C. Ebstein's Anomaly: anatomo- echocardiographic correlation. Cardiovasc Ultrasound 2007;5:43.
5. Donnelly J E, Brown J M, and Radford D J. Pregnancy outcome and Ebstein's anomaly. Br Heart J. 1991; 66(5): 368-71.

6. Boston US, Goldberg SP, Ward KE. Complete repair of Ebstein anomaly in neonates and young infants: A 16year follow-up. J Thorac Cardiovasc Surg 2011 ;141(5):1163-69.

7. Attie F, Rosas M, Rijlaarsdam M, Buendia A, Zabal C, Kuri J, Granados N; The adult patient with Ebstein anomaly. Outcome in 72 unoperated patients. Medicine (Baltimore) 2000;79(1):27-36.

8. Armengol Rofes AJ, Serrano Durán M, Albert Brotons $D C$; Ebstein's anomaly of the tricuspid valve. Apropos 35 cases. An Esp Pediatr 1996 ;44(2):139-44.

9. Radford DJ, Graff RF, Neilson GH. Diagnosis and natural history of Ebstein's anomaly. Br Heart J 1985;54: 517-22.

10. Waickman, LA, Skorton DJ, Varner MW, Ehmke DA, Goplerud CP. Ebstein's anomaly and pregnancy. Am J Cardiol 1984;53:357-58.

11. Copeland WE, Wooley CF, Ryan JM, Runco V, Levin HS.Pregnancy and congenital heart disease. Am J Obstet Gynecol 1963; 86: 107-10. 